\title{
FATIGUE PERFORMANCE OF WELDED JOINTS UNDER VARIABLE AMPLITUDE LOADING SPECTRA
}

\author{
Xu Liu ${ }^{1}$ \\ Brunel University London \& NSIRC \\ Cambridge, United Kingdom \\ Bin Wang \\ Brunel University London \\ London, United Kingdom
}

\author{
Yanhui Zhang \\ TWI Ltd. \\ Cambridge, United Kingdom
}

\begin{abstract}
Offshore pipelines are generally subjected to variable amplitude (VA) loading in service due to waves or ocean currents. Welded joints often represent the most critical locations for fatigue cracking. Use of the current fatigue design guidance, for example, BS 7608, to assess fatigue performance of the welded joints in such structure may lead to inaccurate estimates depending on the nature of the VA loading spectrum. Further studies on the effect of VA loading spectra on fatigue performance of welded joints are needed. In this research, both uniaxial and 4-point bending fatigue tests were performed on non-load carrying fillet welded plates under VA loading spectra to investigate the effects of mean stress and the type of VA loading spectra. The influence of plate thickness was also investigated. Test results suggest that the spectrum with a high constant maximum tensile stress (cycling-down) could significantly degrade fatigue performance of welded joints, with the damage parameter D only at around 0.5. The severity of this type of loading spectrum depends on the mean stress level and the plate thickness. An analytical model has been developed to predict fatigue crack propagation (FCP) by considering the interaction of stresses in the loading spectrum. The model considers the impact of the mean stress generated by the preceding load on FCP in the subsequent cycles. FCP predicted by the model shows a good agreement with the experimental data.
\end{abstract}

Keywords: Fatigue, Welded Joints, Variable Amplitude, , cycling-down spectrum, Crack Propagation.

\section{NOMENCLATURE}

$$
\begin{array}{cl}
D & \text { Miner's sum as damage parameter } \\
\Delta \sigma_{e q u} & \text { equivalent stress range }
\end{array}
$$

${ }^{1}$ Contact author: xu.liu@affiliate.twi.co.uk

$\begin{array}{cl}\Delta \sigma_{\max } & \text { maximum stress range } \\ \Delta K & \text { stress intensity factor } \\ \Delta K_{e f f} & \text { effective stress intensity factor } \\ L & \text { best-fitted parameter } \\ R & \text { loading ratio } \\ P i & \text { relative stress range ratio } \\ \text { VA } & \text { variable amplitude } \\ \text { CD } & \text { cycling-down } \\ \text { CU } & \text { cycling-up } \\ \text { CA } & \text { constant amplitude } \\ \text { FCGR } & \text { fatigue crack propagation rate } \\ \text { RS } & \text { residual stress }\end{array}$

\section{INTRODUCTION}

Most of load bearing structures are subjected to variable amplitude (VA) loading spectrum in service. For instance, highpressure gas transmission pipelines are typically subjected to cycling down (CD) loading spectrum where each load cycle downwards from a constant maximum stress due to internal pressure fluctuations [1]. Current fatigue design guidelines, such as BS 7608 [2], are largely based on experimental data obtained from constant amplitude (CA) loading, in conjunction with a linearly cumulative damage rule, such as the Miner's rule. As defined in the Miner's rule, when fatigue damage, or the Miner's sum $D<1$, the welded joints are considered to be safe in operation. However, extensive studies have shown that this method could be both unduly conservative or non-conservative under some VA loading spectra [4-9]. As a result, it is advised to set the upper limit of $D$ to 0.5 [2] if the effect of the VA loading spectrum is uncertain in order to ensure safety.

The reason for the under-estimate of the fatigue damage under a VA loading spectrum is the treatment of the VA loading spectrum as a combination of different CA loading cycles, assuming that each stress range in a VA loading spectrum causes the same damage as in CA without considering interaction in 
loading cycles. Different interactions, however, in loading cycles in a VA loading spectrum have been observed by extensive studies $[8,10-14]$. In these studies, CD loading spectra and cycling-up (CU) loading spectra, where loading cycles upward from a constant minimum stress, were chosen as typical VA loading spectra and interactions were studied by examining the changes in the fatigue crack growth rate (FCGR) in the following loading cycles after an overload or underload. It has been suggested that FCGR in the subsequent loading cycles is significantly influenced by the prior large loading cycle: it can be retarded by the overload (in CU loading sequence) [10-12] or be accelerated after an underload (CD loading spectrum) $[8,13-$ 14], leading to a higher or lower Miner's sum, respectively.

While the plasticity-induced crack closure was considered as the main reason accounting for the FCGR retardation in a CU loading spectrum [4,14], the mechanism for the FCGR acceleration in CD loading spectra has not been well established. One possible mechanism for the acceleration was suggested to be related to strain hardening where the underload is thought to cause reduction of ductility ahead of crack tip [15-16]. Crack tip blunting is known to take place after an overload, while sharpening is expected after an underload. However, the opposite trend was also found: cracks was blunted after underloads as well [16], though the magnitude was much less than that under an overload. Some studies investigated the crack closure behaviour after an underload and deduced that the reduction in the crack opening stress leads to a higher effective intensity factor $[13,17]$. However, when the loading ratio is relatively high (more than 0.5-0.6 in steels [1]) where the crack closure phenomenon is not usually observed due to high mean stress, the acceleration in FCGR was still observed $[8,18]$.

The influence of the mean stress within the reverse plastic zone ahead of the crack tip on fatigue crack propagation under CD loading spectra was discussed [10]. In the reverse plastic zone, due to mean stress relaxation, fully reversed loading takes place even under purely tensile fatigue loading. After an underload, a tensile mean stress could occur in the following small loading cycles, resulting in an acceleration in the crack propagation rate. Furthermore, a finite element analysis [8] deduced that the acceleration in FCGR after underload can be attributed to the changes in mean stress.

According to the assessment method suggested in standards such as BS7608, the fatigue life of a certain type of welded joint is only dependent on stress ranges applied, independent of stress ratio or mean stress since a high tensile residual stress (RS) is assumed to be present in welds. Indeed, from Gurney's work [5], no significant difference in fatigue life was found when welded joints with longitudinal attachments were loaded with various loading ratios, ranging from -4 to 0.5 . it should be noted that longitudinal fillet welds often have high tensile residual stresses at the toes of the weld ends where fatigue cracking often starts. This observation was found in butt-welded specimens [19] which were loaded under a purely compressive cyclic load with loading ratios ranged from 3 to 1.15 (absolute values of the minimum stress to the maximum), [19], The results showed that the FCG was independent on stress ratio until the minimum stress reached to an extremely low condition, about $-100 \mathrm{MPa}$. On the contrary, some other studies showed better fatigue performance under pulsating compression than pulsating tension loading [21] and suggested that the mean stress correction is necessary to be applied when assessing the fatigue performance of small-size welded joints where the RS stress may be relatively small, or even not exist [20].

Few works have been seen for the effect of the maximum stress on the fatigue performance of welded joints under a $C D$ loading spectrum $[4,20]$. When the maximum stress was reduced from 280 to $147 \mathrm{MPa}$, the Miner sum was only increased slightly [4 which probably could be explained by data scatter [6].

Tilly carried out fatigue testing of two types of welded joints: longitudinal non-load-carrying attachments on plate edges and longitudinal non-load-carrying fillet welded joints [21]. The limited data indicated that the fatigue performance of the joints under pulsating compression was only slightly better than that under pulsating tension loading. This might not be surprising since these two types of welded joints are expected to contain high tensile residual stresses. It is not clearly whether a similar results would be observed in other types of welded joints.

Furthermore, limited studies have shown that thinner specimens appear to have better fatigue resistance under both axial and bending loading [24], and this may be partially caused by reduced tensile RS which was found to be proportional to the plate thickness [25-26].

Therefore, this work investigated the effect of the maximum stress in a CD loading spectrum on the fatigue performance of non-loading carrying transverse attachment welded joints by both uniaxial and bending fatigue tests, on plate specimens with three different thickness. A rig was designed to apply a constant mean stress in the bending mode in order to achieve different level of tensile mean stresses, and to estimate the damage caused by the CU and CD loading spectrum as well.. Based on the test results, in conjunction with data from the open literature, an analytical model taking into account of the residual tensile mean stress was developed to predict crack propagation rate under a $\mathrm{CD}$ loading spectrum.

\section{Test details}

\subsection{Specimen}

Specimens used in this research were non-load carrying transverse attachment welded joints. As in BS 7608, they are categorized as F class, same with $[4-5,8,21]$. The specimen is consisted of a plate with two same thickness attachments, filletwelded on each side, as shown in Figure 1. Specimens were three different thicknesses at $6 \mathrm{~mm}, 12.5 \mathrm{~mm}$ and $25 \mathrm{~mm}$, respectively. And specimen dimensions are shown in Table 1. These specimens were manufactured using S355 steel, and material properties are listed in Table 2. All specimens were tested in the as-welded condition. 

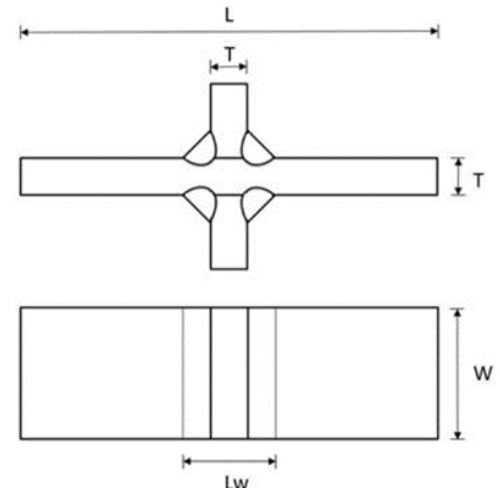

Figure 1. Schematic plot of non-load carrying transverse attachment welded joints

Table 1. Specimen dimensions

\begin{tabular}{cccc}
\hline Thickness & Wideness & Length & Attachment Length \\
$T(\mathrm{~mm})$ & $W(\mathrm{~mm})$ & $L(\mathrm{~mm})$ & $L w(\mathrm{~mm})$ \\
6 & & & 14 \\
12.5 & 100 & 800 & 28.5 \\
25 & & & 51 \\
\hline
\end{tabular}

Table 2. Material properties

\begin{tabular}{lcccc}
\hline $\mathrm{E}(\mathrm{MPa})$ & $\sigma_{y}(\mathrm{MPa})$ & $\sigma_{U T S}(\mathrm{MPa})$ & $K^{\prime}$ & $n$ \\
207000 & 350 & 550 & 960 & 0.16 \\
\hline
\end{tabular}

The cyclic material constants $K^{\prime}$ and $n$ shown in table 2.2 were calculated by Equation (1) [25]:

$b=-0.1667 \log \left(2.1+917 / \sigma_{u}\right)$

$c=-0.7<c<-0.6$

$n=b / c$

$K^{\prime}=\sigma_{y}(0.002)^{-n}$

\subsection{Variable amplitude loading spectrum}

The combination of the stress range and the corresponding number of cycles in one loading block was designed to follow a typical Gassner distribution [26]:

$P i=\left(1-\frac{\log \left(n_{i}\right)}{\log \left(N_{\max }\right)}\right)^{\frac{1}{b}}$

where $P i$ is the relative stress range ratio defined as the ratio of each stress rang to the maximum stress range; $n_{i}$ is the number of cycles corresponding to a specific $P i ; n_{\max }$ is the aimed block length and $b$ is the shape exponent.

To increase the difference between each stress range, the maximum stress range used was $250 \mathrm{MPa}$, which is approximatively $70 \%$ of the yield stress. $n_{\max }$ and $b$ are $1.5 \times 10^{5}$ and 1 respectively. The damage level of the VA loading spectrum could be assessed by an equivalent CA stress range, $\Delta \sigma_{e q u}$, which was calculated in conjunction with the S-N curve obtained under CA loading and the Miner's rule:

$\Delta \sigma_{e q u}=\Delta \sigma_{\max }\left(\frac{\sum p_{i}^{m} n_{i}}{N_{L}}\right)^{m}$

where $m$ is the slop of the S-N curve obtained under CA loading, and $N_{L}$ is the block length, or the total number of loading cycles in a block.

In order to ensure that each stress range in the VA loading spectrum is able to cause fatigue damages, which requires their values to be higher than the constant amplitude fatigue limit (CAFL) defined in BS 7608, and a fairly high equivalent stress to avoid unpractical long testing duration, the spectrum was designed to follow a linear distribution and the minimum value of $P_{i}$ was set as 0.35 , as shown in Figure 2, resulting in $\Delta \sigma_{e q u}=107 \mathrm{MPa}$. Then, the stress ranges and the corresponding number of cycles in the VA spectrum were calculated, as shown in Table 3.

The stress-controlled loading sequence used in the fatigue tests was generated by arranging stress ranges from the VA spectrum downwards from a constant maximum stress in a random order, as shown in Figure 3. The loading sequence was applied repeatedly until fatigue failure occurs.

\subsection{Fatigue test}

The fatigue performance of welded joints under a VA loading spectrum was investigated under both uniaxial and bending mode. In the uniaxial loading mode, all tests were performed under the CD loading sequence. In order to study the effect of the maximum stress in the $\mathrm{CD}$ loading sequence, three different maximum stresses were adopted, at $300 \mathrm{MPa}, 150 \mathrm{Mpa}$ and $87.5 \mathrm{MPa}$, respectively.

To avoid specimen bulking, tests with a low maximum stress were performed under bending mode and a novel rig was designed to apply a mean stress, as shown in Figure 4. The specimen was pre-fixed on the frame by pins and two jacks were installed in parallel to the specimen to produce a positive constant mean stress throughout the fatigue tests process. The mean stress was measured by strain gauges mounted on the top surface of the specimen at a distance 5 times of the plate thickness to the weld toe, to avoid stress concentration effect at the welds. The VA loading was applied by the actuator in the direction perpendicular to the specimen.

Noting that in the bending test, while the top welds were subjected to a CD loading sequence, the bottom welds were loaded by a CU loading sequence, and the applied mean stress became the maximum stress in the CD loading sequence and the minimum stress in the $\mathrm{CU}$ loading sequence, respectively. Two values of the constant mean stress used in this research at 0 and 87.5MPa, respective.

More test details were summarized in Table 4. All fatigue tests were performed at loading frequencies ranged from 3 to 
$6 \mathrm{~Hz}$ in ambient temperature. Fatigue life was defined as the number of cycles when the specimen broke into two pieces.

Table 3. Details of VA loading spectrum

\begin{tabular}{|c|c|c|c|}
\hline $\begin{array}{l}\text { Relative stress range } \\
P i\end{array}$ & $\begin{array}{l}\text { Stress range } \\
(\mathrm{MPa})\end{array}$ & Cycles & Exceedence \\
\hline 1 & 250 & 1 & 1 \\
\hline 0.9 & 225 & 2 & 3 \\
\hline 0.85 & 212.5 & 3 & 6 \\
\hline 0.8 & 200 & 5 & 11 \\
\hline 0.75 & 187.5 & 9 & 20 \\
\hline 0.7 & 175 & 16 & 36 \\
\hline 0.65 & 162.5 & 29 & 65 \\
\hline 0.6 & 150 & 53 & 118 \\
\hline 0.55 & 137.5 & 96 & 213 \\
\hline 0.5 & 125 & 174 & 387 \\
\hline 0.45 & 112.5 & 316 & 703 \\
\hline 0.4 & 100 & 573 & 1276 \\
\hline 0.35 & 87.5 & 1039 & 2315 \\
\hline
\end{tabular}

\subsection{Crack initiation monitoring and growth measurements}

Data on fatigue crack propagation was obtained by both visual inspection and the alternating current potential drop (ACPD) method. Soap solution was applied regularly to aid visual inspection and the crack length at a certain number of loading cycles was monitored. By measuring the beach marks introduced by soap solution in recovered specimens, the fatigue crack depth corresponding to a known crack length can be obtained, as shown in Fig. 5.

\subsection{Residual stress measurement}

As a CD loading spectrum involves a relatively high compressive load, investigation on the residual stress (RS) relaxation under compressive loading was carried out with the $25 \mathrm{~mm}$ thick specimen by the centre hole drilling method. The RS at the weld toe was measured under three conditions: aswelded, and after 2 and 100 load cycles in the CA bending mode. Measurements were made at the location on the top surface $2 \mathrm{~mm}$ to the weld toe and $10 \mathrm{~mm}$ to the mid-width line, subjected to compressive loading, and on the bottom surface exactly opposite to the top one, subjected to tensile loading.

The magnitude of the stress range of the CA bending load cycle equals the maximum stress range in the VA loading spectrum, $250 \mathrm{MPa}$, as the RS relaxation is mainly determined by the largest stress range.

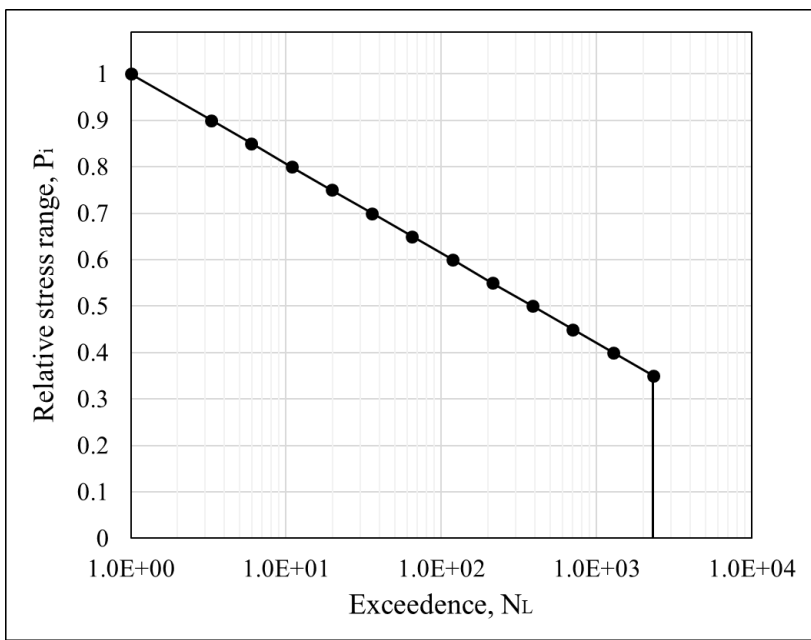

Figure 2. The distribution of $P_{i}$ used in the VA loading spectrum

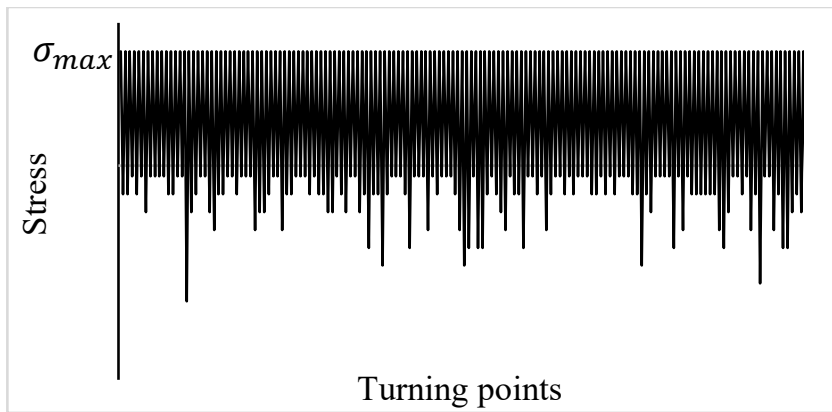

Figure 3. Stress-controlled CD loading sequence used in the fatigue tests

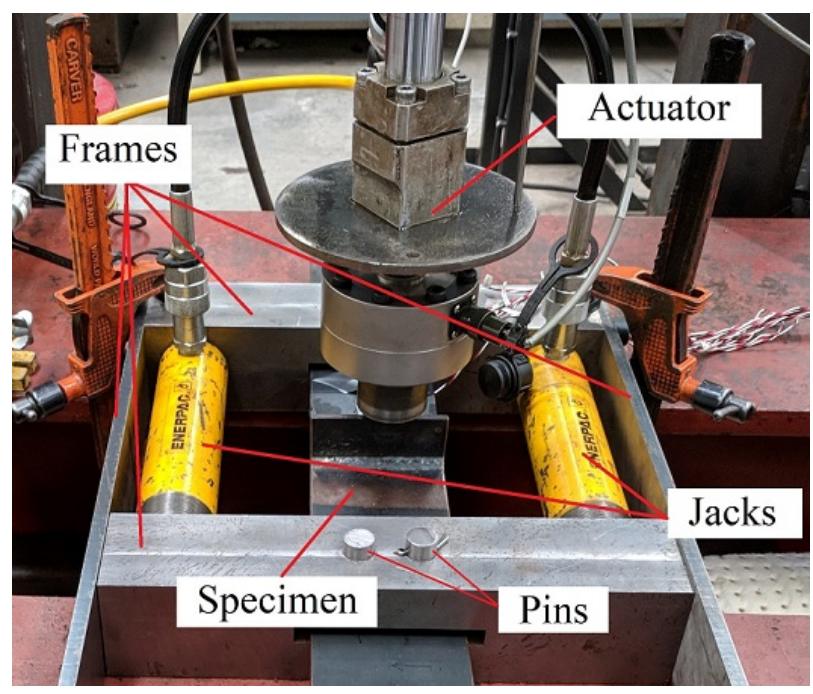

Fig 4. Set-up of bending test

Table 4. Fatigue test details and results

\begin{tabular}{cccccc}
\hline $\begin{array}{c}\text { Specimen } \\
\text { No. }\end{array}$ & $\begin{array}{c}\text { Loading } \\
\text { mode }\end{array}$ & $\begin{array}{c}\text { Thickness } \\
(\mathrm{mm})\end{array}$ & $\begin{array}{c}\text { Max/Mean } \\
\text { stress }(\mathrm{MPa})\end{array}$ & Predicted fatigue life $^{\mathrm{a}}$ & Experimental fatigue life $^{\text {Miner's Sum }}{ }^{\mathrm{a}}$ \\
\hline
\end{tabular}




\begin{tabular}{|c|c|c|c|c|c|c|c|c|c|}
\hline & & & & $\begin{array}{l}\text { No. of cycles } \\
\left(\times 10^{3}\right)\end{array}$ & Blocks & $\begin{array}{l}\text { No. of cycles } \\
\left(\times 10^{3}\right)\end{array}$ & Blocks & & \\
\hline T6_1 & Uniaxial & 6 & 300 & 3574 & 1550 & 1971 & 851 & \multicolumn{2}{|c|}{0.54} \\
\hline T6_2 & & & 150 & & & 1802 & 778 & \multicolumn{2}{|c|}{0.51} \\
\hline T125_1 & & 12.5 & 300 & 2219 & 958 & 947 & 409 & \multicolumn{2}{|c|}{0.43} \\
\hline T125_2 & & & 150 & & & 2612 & 1128 & \multicolumn{2}{|c|}{1.18} \\
\hline T125_3 & & & 87.5 & & & 4315 & 1863 & \multicolumn{2}{|c|}{1.94} \\
\hline T25_1 & & 25 & 300 & 957 & 413 & 586 & 253 & \multicolumn{2}{|c|}{0.61} \\
\hline T25_2 & & & 150 & & & 730 & 315 & \multicolumn{2}{|c|}{0.76} \\
\hline & & & & & & & & Top $^{\mathrm{b}}$ & Bottom $^{b}$ \\
\hline B6_1 & Bending & 6 & 87.5 & 9889 & 4270 & 15735 & $\begin{aligned} & 2326 \\
+ & 26738^{c}\end{aligned}$ & $>3^{c}$ & $>3^{c}$ \\
\hline B125_1 & & 12.5 & 87.5 & 5026 & 2170 & 4407 & 1903 & $>>0.88^{\mathrm{d}}$ & 0.88 \\
\hline B25_1 & & 25 & 0 & 1989 & 859 & 4725 & 2040 & $>>2.37^{\mathrm{d}}$ & 2.37 \\
\hline
\end{tabular}

Notes: ${ }^{a}$ calculated according to S-N curve obtained under CA loading. ${ }^{b}$ results for the top (bottom) welds which were subjected to CD (CU) VA loading in the bending test. ${ }^{c}$ after 2326 blocks, the minimum $P_{i}$ of the VA loading spectrum was changed from 0.35 to 0.5 and 26736 more blocks were loaded before the test was stopped. ${ }^{c}$ run out. ${ }^{d}$ failure occurred at bottom welds and no crack was found at top welds, as results the Miner's sum for top welds should be much higher than that of bottom welds

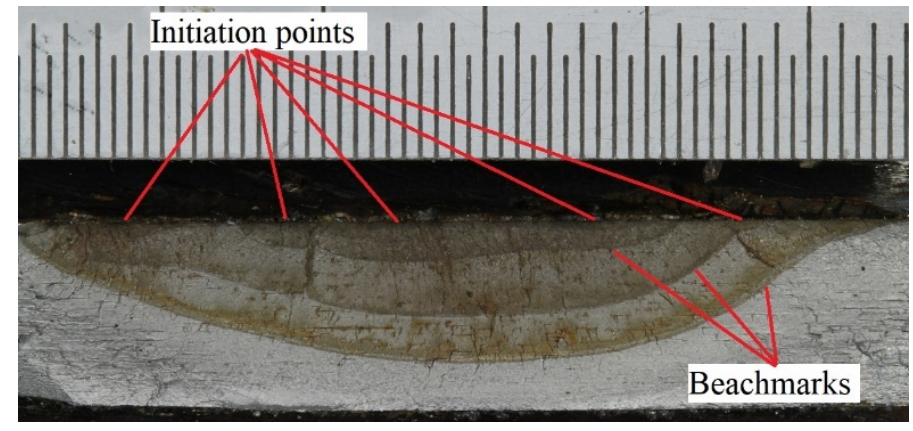

Figure 5. Typical beach marks and crack initiation points obtained on the fracture surface of specimen T6_1

Table 5. Details of RS measurement of a welded plate of $25 \mathrm{~mm}$ in thickness

\begin{tabular}{lcc}
\hline Condition & $\begin{array}{c}\text { RS on top } \\
(\mathrm{MPa})\end{array}$ & $\begin{array}{c}\text { RS on bottom } \\
(\mathrm{MPa})\end{array}$ \\
\hline As-welded & 252 & 213 \\
After 2 cycles & 183 & 166 \\
After 100 cycles & 161 & 150 \\
\hline
\end{tabular}

\section{Results and discussion}

\subsection{Residual stress measurement}

RS relaxation was studied at both top and bottom welds, which were subjected to tensile and compressive loading, respectively, as shown in Table 5. The average value of RS in as-welded condition is $232 \mathrm{MPa}$, at $65 \%$ of the material yield stress. After 2 loading cycles, the RS was significantly decreased by about $60-70 \mathrm{MPa}$ in both top and bottom welds, and no obvious reduction was found after more cycles. A similar trend was reported in [27]. Results of top welds also indicate that purely compressive loading can cause RS relaxation as well, and the magnitude of reduction is similar to that cause by purely tensile loading.

\subsection{Fatigue tests}

All specimens loaded by uniaxial loading failed at the weld toe. By examining the fracture surface, multiple fatigue cracks can be seen initiated from different sites at the weld toe and propagated simultaneously before coalescence taking place, as shown in Figure 5.

In bending tests, specimen B125_1 $\left(\sigma_{\text {mean }}=87.5 \mathrm{MPa}\right.$ and $\mathrm{T}=12.5 \mathrm{~mm})$ and $\mathrm{B} 25 \_1\left(\sigma_{\text {mean }}=0\right.$ and $\left.\mathrm{T}=25 \mathrm{~mm}\right)$ both failed at one of the bottom welds which were subjected to $\mathrm{CU}$ loading spectrum. The fracture surface was observed under optical microscope and no crack was found initiated at top welds subjected to CD loading spectrum. The top welds were thus counted as run out. However, this was not the case in the $6 \mathrm{~mm}$ thickness specimen. Test B6_1 ran out and after breaking the specimen in liquid nitrogen, a crack was observed propagating from the top weld as can be seen in Figure 6, while no crack was found at the bottom weld. This could be explained by misalignment caused by the welded in the thin specimen. When a constant load was applied, due to misalignment a positive secondary bending stress was generated at top welds, while at bottom welds, a negative secondary bending stress was introduced. Consequently, as the strain gauge was applied on the top surface, the top welds could be loaded with the target mean stress, but the bottom welds were loaded with a much lower mean stress that could lead to a longer fatigue life. 


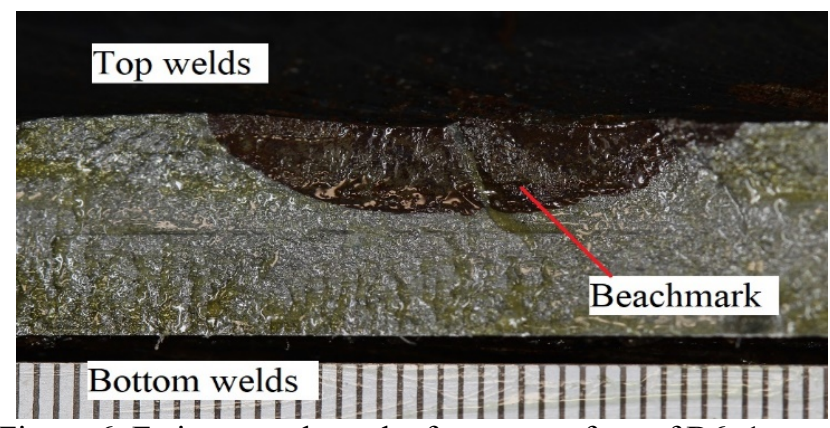

Figure 6. Fatigue crack on the fracture surface of B6_1

The S-N curve used in current research was obtained from a previous project where the specimen was loaded under a CA loading condition with a constant maximum stress at $300 \mathrm{MPa}$ in both uniaxial and bending modes. For comparison, the results obtained under the $C D$ loading spectrum with maximum stress of $300 \mathrm{MPa}$ and $147 \mathrm{MPa}$ form [4] were considered. Miner's sums $D$ for most of the specimens did not show a significant increase when the maximum stress was reduced from $300 \mathrm{MPa}$ to $150 \mathrm{MPa}$, but a relatively high increase was observed in the $12.5 \mathrm{~mm}$ thick specimen. By decreasing the maximum stress further to $87.5 \mathrm{MPa}$ or $0, D$ increased dramatically, and the magnitude varied inversely to the plate thickness. Test results are shown in Table 4, and the relationship between Miner's sum and the maximum stress was shown in Figure 7.

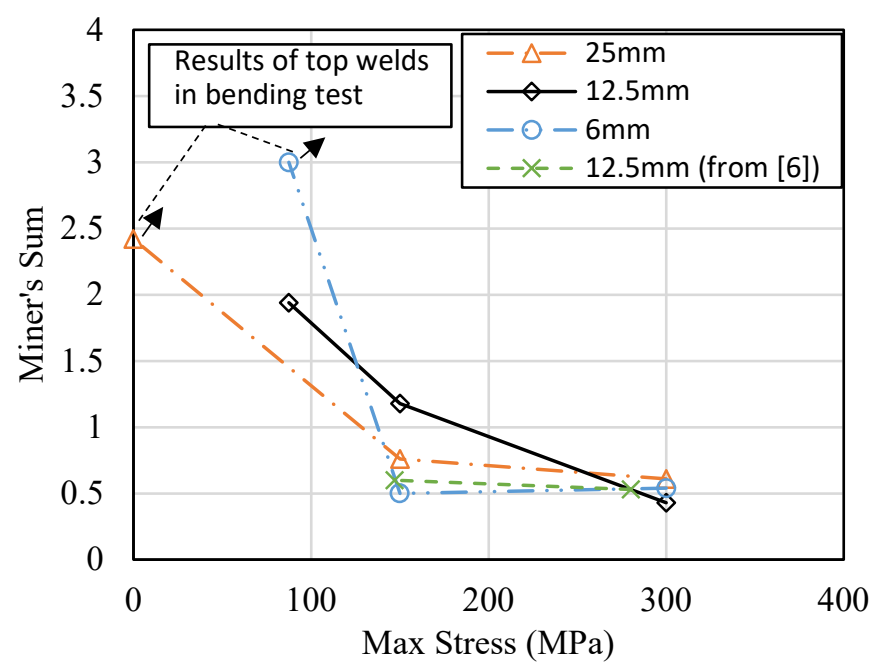

$\boldsymbol{\nabla}$ : run out

Figure 7. The Miner's sum obtained under CD loading spectrum with different maximum stresses

Following conclusions can be drawn from these results:

1. When the maximum stress in the CD loading spectrum is relatively high approximately $80 \%$ the yield stress of the material, the Miner's sum is around 0.5 , which is similar with the results obtained in other studies $[4,8,21]$.

2. By decreasing the maximum stress from $300 \mathrm{MPa}$ to $150 \mathrm{MPa}$, no significant change in Miner's sum $D$ is observed. The same trend was reported in [4] which studied longitudinal attachment fillet welded joints with high RS loaded under CD loading spectrum. It shows familiar Miner's sum values when the maximum stress was varied from $280 \mathrm{MPa}$ to $147 \mathrm{MPa}$. It worth to notice that in this case, some loading cycles with a relatively large stress range have involved compressive part which implied that the changing mean stress in this region has a less effect on the fatigue performance of welded joints. The residual stress is a reasonable explanation for this phenomenon.

3. As the maximum stress is reduced to $87.5 \mathrm{MPa}$, or even lower to 0 , a dramatical increase in the Miner's sum is seen, reaching to 3 or even higher. This could be explained by the RS relaxation during the cyclic load. For example, the measured RS at the weld toe in the $25 \mathrm{~mm}$ thick specimen was $150 \mathrm{MPa}$ after cyclic loading, this will not increase the CD loading spectrum with a zero mean stress to the same high level as in the situation when the maximum stress is 150 and $300 \mathrm{MPa}$.

4. No strong effect of thickness can be seen when the maximum stress is higher than $150 \mathrm{MPa}$. Nevertheless, as the maximum stress decreases to a lower value, say $87.5 \mathrm{MPa}$, the Miner's sum of the $6 \mathrm{~mm}$ specimen is higher than that of the $12.5 \mathrm{~mm}$ specimen, implying a trend that thinner specimens may have a better fatigue life than thicker specimens under a CD loading spectrum with a relatively low maximum stress. This conclusion needs further confirmation by more tests.

5. $D=0.5$ may be a reasonable upper limit value to assess the fatigue life of welds under a CD loading spectrum when the maximum stress is higher than half of the yield stress. But it becomes conservative as the maximum stress decreases continuously. Further studies are needed to study the relationship between the Miner's sum and the maximum stress in a CD loading spectrum.

6. By assuming the stress at the crack tip cannot exceed the yield stress of the material, the residual stress can shift the mean stress of the applied nominal stress range to the yield stress level, resulting in that the actual stress ahead of the crack tip is always cycling down from the yield stress [4]. In this case, even if the applied stress is compressive, it will cause the same damage as the tensile stress as long as the stress ranges are the same. So, the cycling up and cycling down VA loading spectra should cause the same damage, which means in a bending-fatigue test, the upper welds have the equal chance as the lower welds to fail. However, results from the bending test cannot support this assumption as observed failure only occurs at bottom welds, while no crack has been found in the upper welds. This means a $\mathrm{CD}$ loading spectrum may cause less damage than a CU loading spectrum if cycling down or up from the same stress level.

\section{Fracture mechanics analysis}

\subsection{Mechanism}

As mentioned in the introduction, neither crack closure nor blunting is a proper mechanism to explain the acceleration of the FCGR in the subsequent loading cycles under a CD loading spectrum with a high maximum stress (high loading ratio $\mathrm{R}$ ). 
Hence, an analytical model has been developed according to the residual mean stress mechanism proposed in [16] to predict the fatigue crack propagation in welded joints under such a loading condition.

Due to the mean stress relaxation, in the reverse plastic zone ahead of the crack tip, a fully reserved local hysteresis loop exists even under purely tensile cyclic fatigue loading. As a result, when a CD loading spectrum, as shown in Figure 8(a), is applied, the local hysteresis loop for the UL is to be fully reserved, as shown in Figure 8(b). However, this is not the case for the loop of small cycles following the UL, where a tensile residual mean stress is introduced in comparison with the loop before the UL or under a CA loading condition. The residual stress is considered as the main reason accounting for the FCGR acceleration.

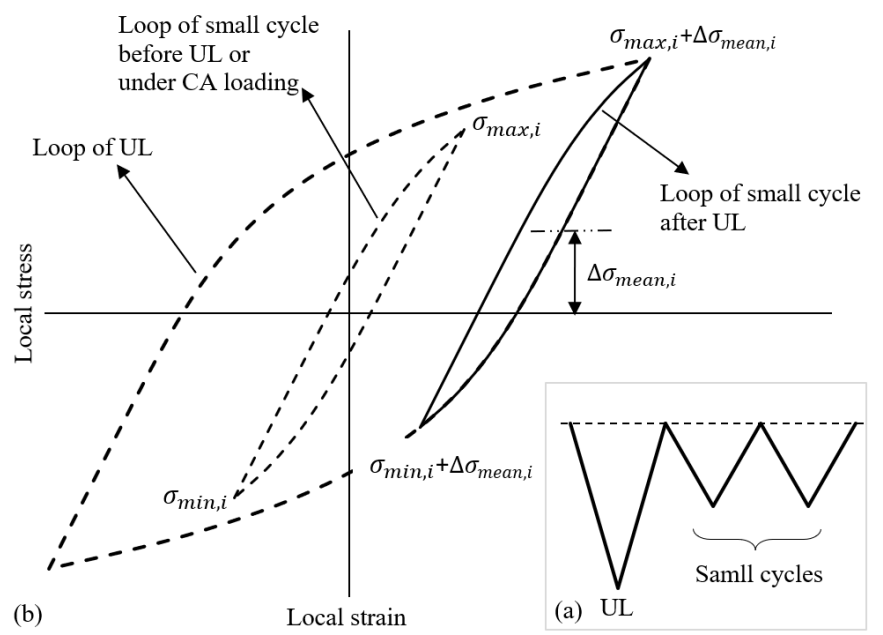

Figure 8. The mechanism of residual mean stress in the reverse plastic zone ahead of the crack tip. (a) typical CD loading spectrum. (b) Hysteresis loops corresponding to different loading cycles

The effect of the residual mean stress has not been quantitated yet, so in this research, it is estimated in terms of the change in the local loading ratio before and after the UL.

The FCGR is calculated by a widely accepted method where an effective stress intensity factor is considered in Paris' Law [14]:

$=A\left(\Delta K_{e f f}\right)^{m} \quad \frac{d a}{d N}$

where

$=U_{\text {eff }} \Delta K$

$\Delta K_{e f f}$

$U_{\text {eff }}$ is a parameter that takes into account the interaction between loading cycles in a VA amplitude loading spectrum and is calculated in different ways depending on the mechanisms. In this paper, $U_{e f f}$ was develop based on the residual mean stress mechanism and correlated with the changes in the local loading ratio:

$U_{\text {eff }}$

$=\left[\frac{U\left(R_{i}^{\prime}\right)}{U\left(R_{i}\right)}\right]^{L}$

where $L$ is a best-fit parameter which can be determined by experimental results, and $U(R)$ is a function taking into account the effect of the loading ratio [27]:

$U(R)$
$=\left\{\begin{array}{rr}\frac{1}{1.5-R} & -5<R<0.5 \\ 1 & R>0.5\end{array}\right.$

Form Figure 8, it can deduce that the local loading ratio $\mathrm{R}$ before the UL or under a CA loading spectrum is constant, $R_{i}=$ -1 , while after $\mathrm{UL}$, the loading ratio changes to:

$R_{i}^{\prime}$

$=\frac{\sigma_{\text {min }, i}+\Delta \sigma_{\text {mean }, i}}{\sigma_{\text {max }, i}+\Delta \sigma_{\text {mean }, i}}$

where $\sigma_{\min , i}$ is the minimum local stress of the small cycle before UL or under CA loading; $\sigma_{\max , i}$ is the maximum local stress of the small cycle before UL or under CA loading; and $\sigma_{\text {mean }, i}$ is the residual mean stress in the small cycle after UL.

Calculation of the intensity factor range $\Delta K$ is based on British Standard BS 7910[28] and the crack propagation rate $A$ is determined by the on-stage FCGR mean curve at $2.31 \times$ $10^{-13}$. The local hysteresis loop for different loading cycles is calculated by Ramberg-Osgood equation in conjunction with Neuber's rule. More details can be found in [29].

\subsection{Crack propagation data for validation}

To validate the analytical model proposed, in addition to the experimental data from the current research, data form the open literature $[4,8]$ are used as the testing condition in these two works is similar to that of the current research. Hence, the data on the crack propagation is used to validate the new model.

\subsection{Input parameters}

The value of $L$ used in Eq. (5) is determined by the 5 test results from the open literature [4]. These tests were performed under a $\mathrm{CD}$ loading spectrum with the constant maximum stress at $280 \mathrm{MPa}$, but with different minimum $P i$ values ranged from 0.1 to 0.25 . Based on th(etin)odel proposed, the number of blocks from the initial crack size to the final crack size is calculated with the different value of $L$. Calculated and experimental results are shown in Figure 9. It can be seen that a proper value of $L$ should range from 0.3 to 0.5 . In this case, $L$ was chosen as 0.35 in 
further studies. Prediction of the crack propagation in these 5 tests was shown in Figure 10.

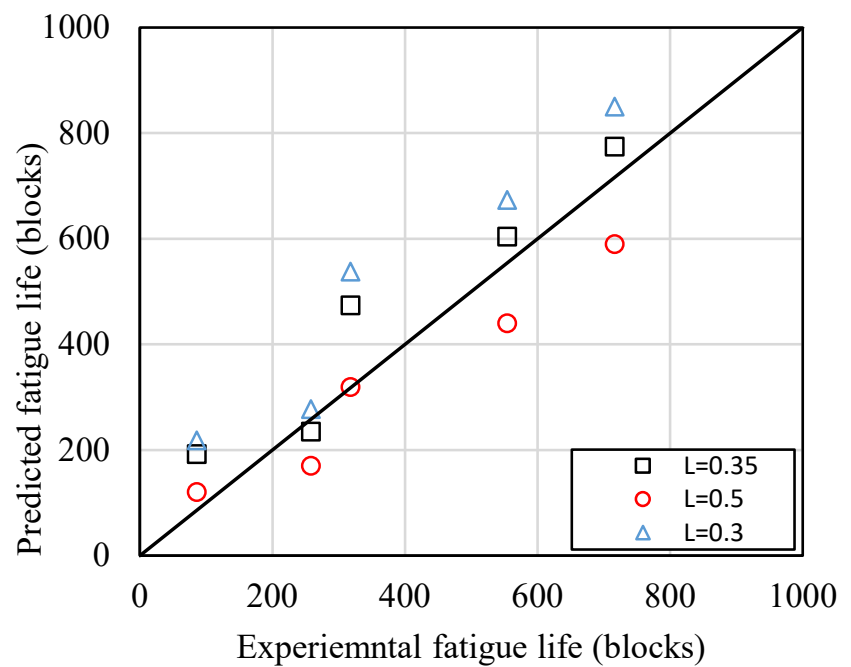

Figure 9. Comparison between predicted and experimental fatigue life with different $L$ value.

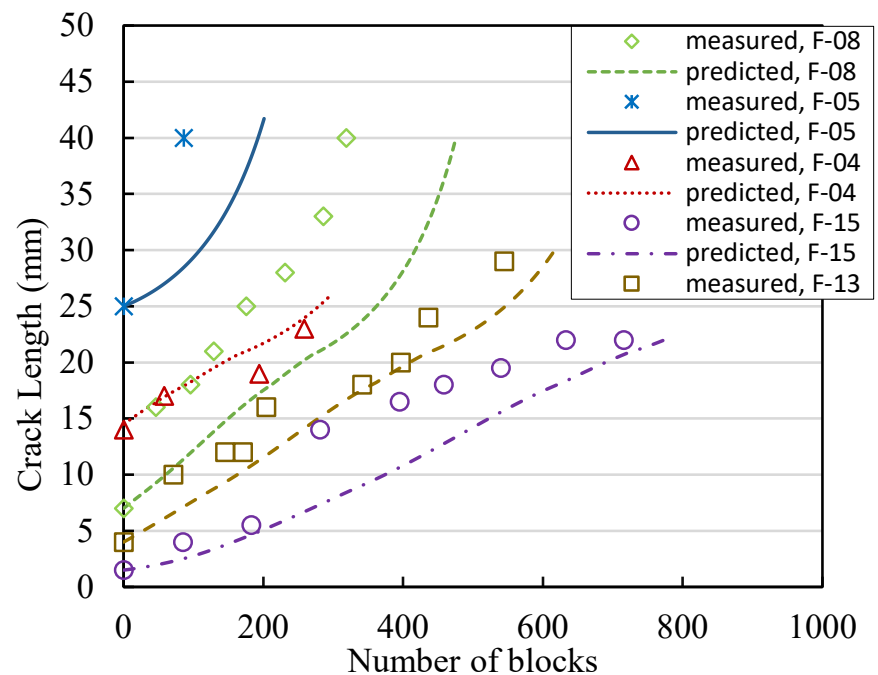

Figure 10. Prediction of crack propagation with $L=0.35$.

By measuring beach marks on the fracture surface, the aspect ratio of fatigue cracks used in the prediction can be determined as 0.2 for the results from [4], and 0.25 for those from [8] and the current research.

\subsection{Validation}

As the new model is proposed under a $\mathrm{CD}$ loading spectrum with a high maximum stress, three experimental results obtained from T6_1, T125_1 and T25_1 in current research and five results from [8] are chosen to validate this model. The comparisons between the prediction and experimental results are shown in Figure 11 and 12.
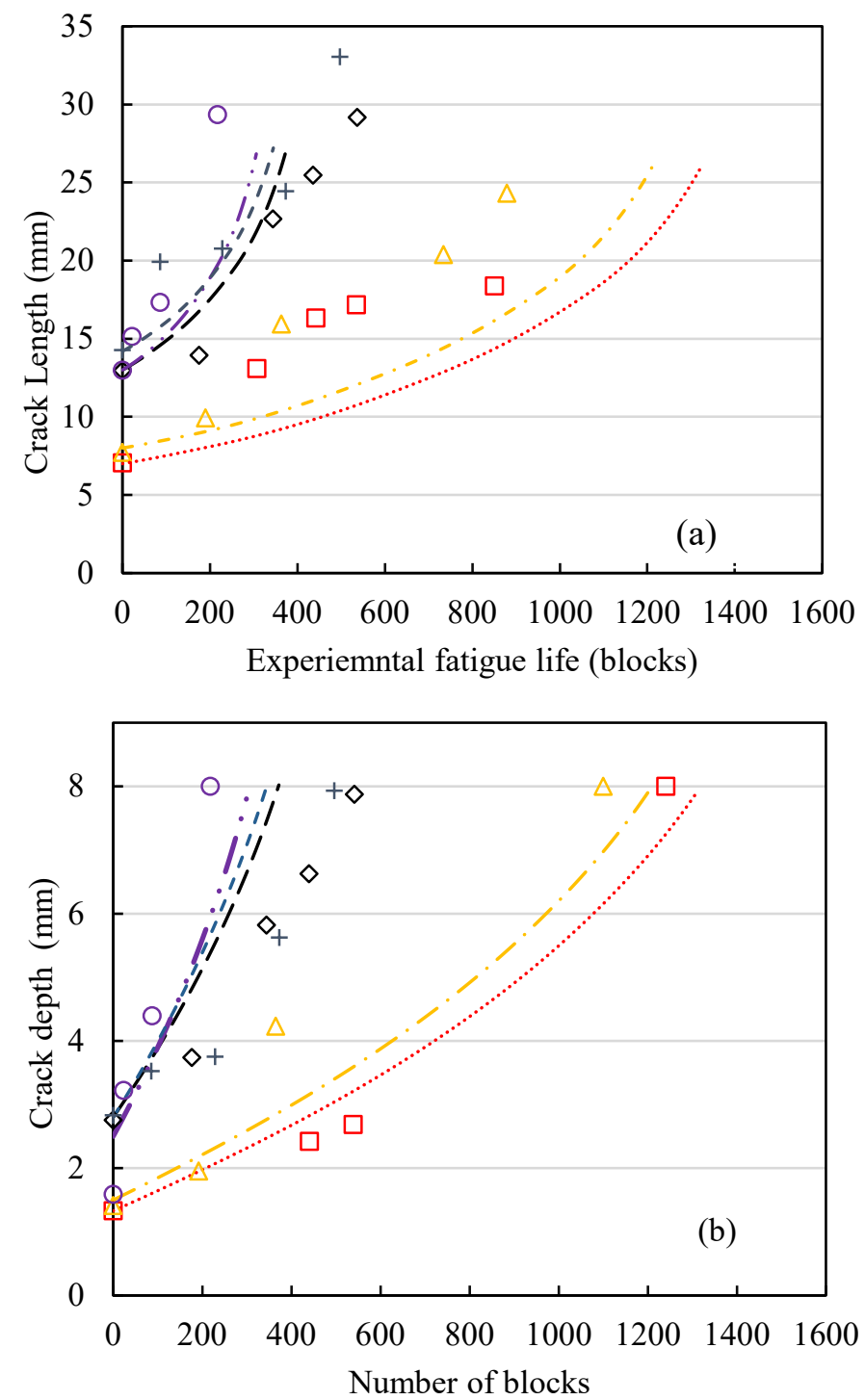

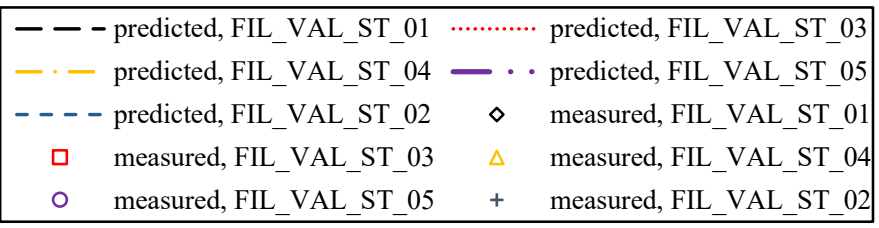

Figure 11. Comparison between the predicted and experimental fatigue crack propagation from [8]. (a) Crack length; (b) Crack depth

It can be seen that:

1. Predicted results in both the length and depth aspects agree well with the experimental results.

2. Predictions of the crack length are better than those of the crack depth, since crack propagation is affected by the surface condition adjacent to the weld toe. For tested specimens, welding was conducted manually with variation in quality.

3. A significant difference is seen from test $\mathrm{T} 6$ 1, this may be due to the irregularity of change in the crack aspect ratio, as 
shown in Figure 6. The crack was initiated at multiple points and coalesce took place at the very beginning, resulting in a shallow crack with the loading aspect ratio of about 0.06 . As the crack grew, the ratio was gradually increased to about 0.25 by the end of the test. However, the calculation was made with an initial aspect ratio of 0.06 , so it led to a conservative prediction. A calculation with the aspect ratio of 0.2 , which equals the average value obtained in the current research, was made and results show a better prediction, as illustrated in Figure 12(a).

\section{Conclusions}

The effects of the VA loading spectrum on the fatigue performance of transverse and longitudinal non-load carrying fillet welded joints were studied by fatigue tests. And an analytical model based on the residual mean stress mechanism was developed to predict the FCGR under a CD loading spectrum with a high maximum stress. From the experimental results and the model, following conclusions can be drawn:

1. Under a CD loading spectrum with a high maximum stress, the fatigue life of the welded joints is decreased significantly, and the cumulative damage calculated based on the S-N curve obtained from CA test is about 0.5 .

2 . The fatigue life of welded joints man be influenced by the maximum stress in a CD loading spectrum when it reduced to a certain low level.

3. While thickness has no effect on the fatigue life when the maximum stress is high, thin specimens show a better fatigue performance when the maximum stress decreases to a lower level.

4. The residual mean stress is able to account for the FCGR acceleration after the UL in a CD loading spectrum and the model proposed based on this mechanism is able to provide a good prediction of the crack propagation.

\section{ACKNOWLEDGEMENTS}

This publication was made possible by the sponsorship and support of TWI and Brunel University London. The work was enabled through and undertaken at the National Structural Integrity Research Centre (NSIRC), a postgraduate engineering facility for industry-led research into structural integrity established and managed by TWI through a network of both national and international Universities.
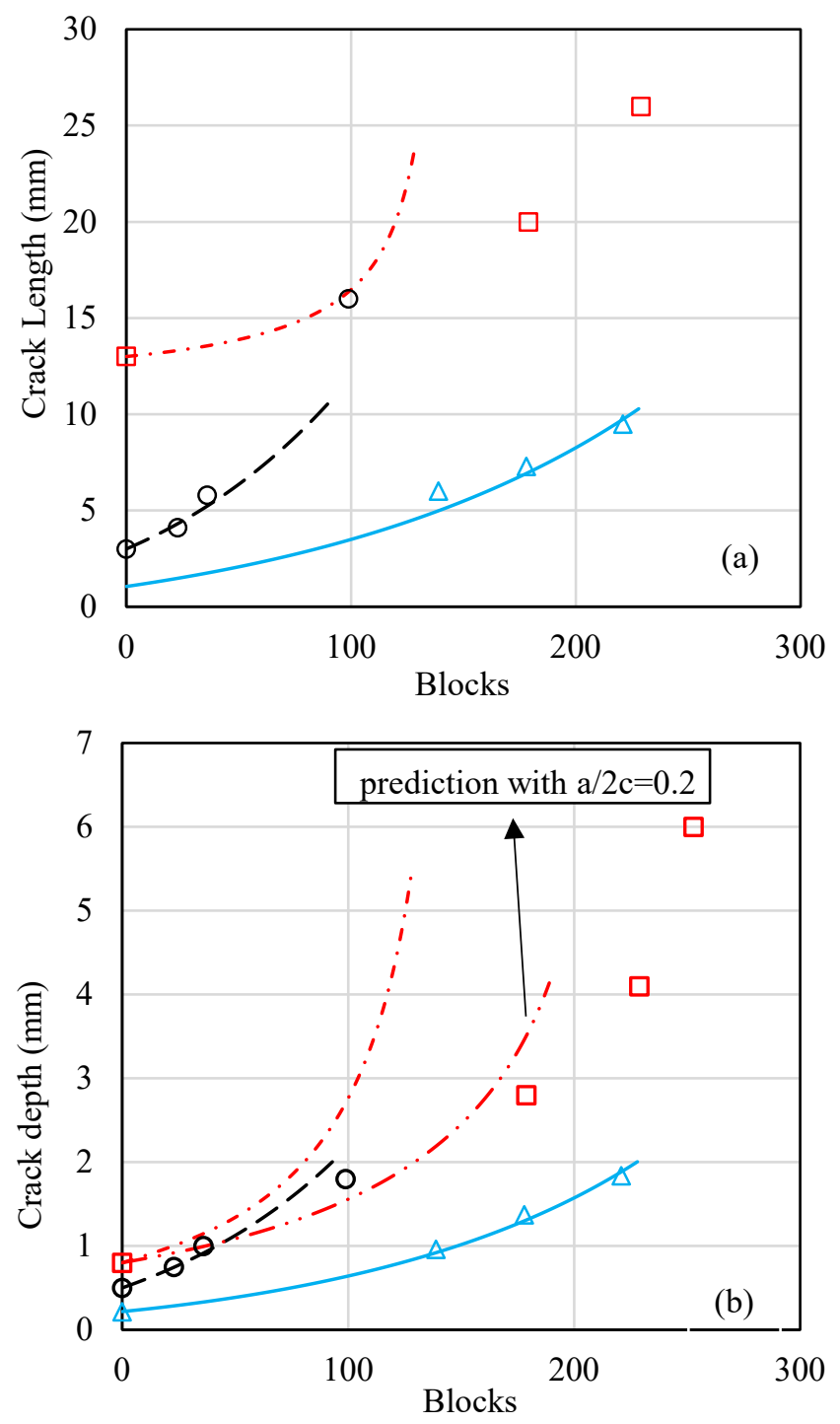

\begin{tabular}{|ccc|}
\hline- predicted, T12.5_1 & - & - predicted, T25_1 \\
$-\cdots-$ predicted, T6_1 & $\Delta$ & measured, T12.5_1 \\
$\circ \quad$ measured, T25_1 & $\square$ & measured, T6_1 \\
$-\cdots-$ predicted, T6_1 (a/2c=0.2) & & \\
\hline
\end{tabular}

Figure 12. Comparison between the predicted and experimental fatigue crack propagation from current research.

(a) Crack length; (b) Crack depth

\section{REFERENCES}

[1] Yu, M., 2015. Crack growth behaviour of pipeline steels under variable pressure fluctuations in a near-neutral $\mathrm{pH}$ environment (Doctoral dissertation, University of Alberta).

[2] BS 7608. Fatigue design and assessment of steel structure. British Standards Institution, London; 2014.

[3] Bosch, A., Vormwald, M., Schackert, S. and Schweizer, C., 2018. Fatigue life assessment of welded joints made of the stainless steel $\mathrm{X} 6 \mathrm{CrNiNb} 18-10$ for thermomechanical and 
variable amplitude loading: Lebensdauerbewertung für Schweißnähte des Edelstahls X6CrNiNb18-10 unter thermomechanischer Belastung und variablen Amplituden. Materialwissenschaft Werkstofftechnik, 49(3), pp.316-331.

[4] Zhang, Y.H. and Maddox, S.J., 2009. Investigation of fatigue damage to welded joints under variable amplitude loading spectra. International Journal of fatigue, 31(1), pp.138-152.

[5] Gurney, T.R., 2006. Cumulative damage of welded joints. Woodhead Publishing.

[6] Tilly, G.P. and Nunn, D.E., 1980. Variable amplitude fatigue in relation to highway bridges. Proceedings of the Institution of Mechanical Engineers, 194(1), pp.259-267.

[7] Berger, C., Eulitz, K.G., Heuler, P., Kotte, K.L., Naundorf, H., Schuetz, W., Sonsino, C.M., Wimmer, A. and Zenner, H., 2002. Betriebsfestigkeit in Germany-an overview. International Journal of Fatigue, 24(6), pp.603625.

[8] Doré, M.J., 2016. An investigation of fatigue crack growth acceleration (Doctoral dissertation, Open University).

[9] Möller, B., Wagener, R., Hrabowski, J., Ummenhofer, T. and Melz, T., 2015. Fatigue life of welded high-strength steels under Gaussian loads. Procedia Engineering, 101, pp.293301.

[10] Schijve, J., Skorupa, M., Skorupa, A., Machniewicz, T. and Gruszczynski, P., 2004. Fatigue crack growth in the aluminium alloy D16 under constant and variable amplitude loading. International Journal of Fatigue, 26(1), pp.1-15.

[11] Shin, C.S. and Hsu, S.H., 1993. On the mechanisms and behaviour of overload retardation in AISI 304 stainless steel. International Journal of Fatigue, 15(3), pp.181-192.

[12] Ding, Z., Wang, X., Gao, Z. and Bao, S., 2017. An experimental investigation and prediction of fatigue crack growth under overload/underload in Q345R steel. International Journal of Fatigue, 98, pp.155-166.

[13] Zitounis, V. and Irving, P.E., 2007. Fatigue crack acceleration effects during tensile underloads in 7010 and 8090 aluminium alloys. International journal of fatigue, 29(1), pp. 108-118.

[14] Salvati, E., Sui, T., Zhang, H., Lunt, A.J., Fong, K.S., Song, X. and Korsunsky, A.M., 2016. Elucidating the mechanism of fatigue crack acceleration following the occurrence of an underload. Advanced Engineering Materials, 18(12), pp. 2076-2087.

[15] Sharifimehr, S., Fatemi, A., Cha, S.C., Bae, M.K. and Hong, S.H., 2016. Fatigue behavior of AHSS lap shear and butt arc welds including the effect of periodic overloads and underloads. International Journal of Fatigue, 87, pp.6-14.
[16] Fleck, N.A., 1985. Fatigue crack growth due to periodic underloads and overloads. Acta Metallurgica, 33(7), pp.1339-1354.

[17] Khalil, M. and Topper, T.H., 2003. Prediction of crackopening stress levels for 1045 as-received steel under service loading spectra. International Journal of Fatigue, 25(2), pp.149-157.

[18] Hassanipour, M., Verreman, Y., Lanteigne, J. and Chen, J.Q., 2016. Effect of periodic underloads on fatigue crack growth in three steels used in hydraulic turbine runners. International journal of fatigue, 85, pp.40-48.

[19] Ohta, A., Kosuge, M., Mawari, T. and Nishijima, S., 1988. Fatigue crack propagation in tensile residual stress fields of welded joints under fully compressive cycling. International Journal of Fatigue, 10(4), pp.237-242.

[20] Kihl, D.P. and Sarkani, S., 1999. Mean stress effects in fatigue of welded steel joints. Probabilistic engineering mechanics, 14(1-2), pp.97-104.

[21] Tilly, G.P., 1985. Fatigue of land-based structures. International Journal of Fatigue, 7(2), pp.67-78.

[22] Zhang, Y.H. and Maddox, S.J., 2009. Fatigue life prediction for toe ground welded joints. International Journal of Fatigue, 31(7), pp.1124-1136.

[23] Heuler, P. and Klätschke, H., 2005. Generation and use of standardised load spectra and load-time histories. International Journal of Fatigue, 27(8), pp.974-990.

[24] Sun Xing, 2019: Research Report, "Improved bending correction factor for fatigue assessment of welded joints", TWI CRP report, to be published soon (confidential to TWI Industrial Members).

[25] Qiang, B., Li, Y., Yao, C., Wang, X. and Gu, Y., 2018. Through-thickness distribution of residual stresses in Q345qD butt-welded steel plates. Journal of Materials Processing Technology, 251, pp.54-64.

[26] Andreassen, M.J., Yu, Z., Liu, S. and Nielsen, J.H., 2017. 02.08: The influence of plate thickness on the welding residual stresses from submerged arc welding in offshore steel structures. ce/papers, 1(2-3), pp.499-504.[27] Booth GS, Maddox SJ. Correlation of fatigue crack growth data obtained at different stress ratios. In: Mechanics of fatigue crack closure, ASTM STP 982; 1988. p. 516-27.

[28] BS 7910. Fatigue design and assessment of steel structure. British Standards Institution, London; 2013.

[29] Dowling NE. Mechanical behaviour of materials. Pearson, 2012. 